\title{
A clinical study of impact of anaemia in pregnancy on maternal and neonatal outcome
}

\author{
Lokeshwari K. $^{1}$, Anju Arpana ${ }^{1 *}$, Manoj Kumar Mudigubba ${ }^{2}$
}

\begin{abstract}
${ }^{1}$ Department of Obstetrics and Gynecology, Basaveshwara Medical College and Hospital, Chitradurga, Karnataka, India

${ }^{2}$ Faculty of Pharmacy, Ramaiah University of Applied Science, Bangalore, Karnataka, India
\end{abstract}

Received: 14 November 2018

Accepted: 06 December 2018

\author{
*Correspondence: \\ Dr. Anju Arpana, \\ E-mail: dr.anju.a@gmail.com
}

Copyright: (c) the author(s), publisher and licensee Medip Academy. This is an open-access article distributed under the terms of the Creative Commons Attribution Non-Commercial License, which permits unrestricted non-commercial use, distribution, and reproduction in any medium, provided the original work is properly cited.

\begin{abstract}
Background: The aim is to study effect of anaemia in obstetrics patients during antepartum, intrapartum and postpartum and to find the incidence of maternal and neonatal morbidity and mortality in those patients.

Methods: A prospective clinical study was conducted on patients receiving obstetric care at Basaveshwara Medical College and Hospital from July 2016 to July 2018.Pregnant women with Hb less than 8g were included in the study to determine the outcome of pregnancy in severe anaemia and determine the causes of anaemia. Acute cases of obstetrical haemorrhages as in antepartum and postpartum haemorrhages and all medical and surgical high-risk factors except anaemia, were excluded from the study.

Results: A total of 200 pregnant anaemic patients with haemoglobin less than $8 \mathrm{~g} / \mathrm{dl}$ were included in the study. The patients were divided into two groups based on haemoglobin concentration at first presentation. Patients with haemoglobin level less than $5 \mathrm{~g} / \mathrm{dl}$ were included in group $\mathrm{A}(\mathrm{N}=44,22 \%)$, and rest of the patients were included in group $\mathrm{B}(\mathrm{N}=156,78 \%)$. Most commonly observed complications in the study were preeclampsia and eclampsia (46 cases), preterm labour (46 cases) and IUGR (30 cases). In both group of patients, the commonest cause of anaemia in pregnancy was iron deficiency. The greater the severity of anaemia in pregnancy, greater was the risk of preeclampsia, preterm delivery, low birth weight and stillbirth.

Conclusions: This study reveals that severe anaemia which is commonly observed in the pregnancy in our country, gives rise to maternal and perinatal morbidities and mortalities.
\end{abstract}

Keywords: Anemia, Haemoglobin, Perinatal outcome

\section{INTRODUCTION}

Anaemia is the commonest haematological disorder occurring in pregnancy in India. It affects 1.62 billion people globally, corresponding to $24.8 \%$ of world population. ${ }^{1}$ In India, anaemia is a physiological process of pregnancy in mild degree, but becomes pathological if left undetected and untreated.

World Health Organization (WHO)defines anaemia in pregnancy as haemoglobin concentration less than
$11 \mathrm{gm} / \mathrm{dl}$ and haematocrit less than $0.33 .^{2}$ The center for disease control and prevention (1990) defines anaemia as $\mathrm{Hb}$ less than $11 \mathrm{gm} / \mathrm{dl}$ in the first and third trimester and less than $10.5 \mathrm{gm} / \mathrm{dl}$ in second trimester. ${ }^{3}$

WHO has estimated that prevalence of anaemia in pregnant women is $14 \%$ in developed countries, $51 \%$ in developing countries and $65-75 \%$ in India. ${ }^{4}$ Iron deficiency is the most common cause and even in the developed country, an estimated $30-40 \%$ of pre-school children and pregnant women have iron depletion. The 
incidence is more in rural population and in women belonging to poor socio-economic groups, poor nutrition thus being the leading cause of anaemia.

Other causes are worm infestation, frequent pregnancies at short interval, excess loss of blood at previous deliveries or during menses, bleeding piles, peptic ulcer, chronic infection and other blood dyscrasias, malaria etc.

Diet of an average class of Indian females is inadequate in iron, which gives very little opportunity to store iron and enable them to meet the demands of foetus when pregnancy supervenes. So, a diet inadequate in iron combined with the factors mentioned above, which are quite common in India, a female even if not actually anaemic is already depleted of essential haemopoetic factors and is in the borderline of developing anaemia. In such a female, anaemia rapidly develops as a result of increased demand in pregnancy.

With great advances in management, antenatal iron and folic acid supplementations, nutrition education and increased social awareness, the incidence of anaemia is gradually decreasing, but it is still a major problem in India. It is the commonest and more easily preventable medical disorder of pregnancy. The present study is to assess the maternal and foetal outcome in pregnancies complicated with severe anaemia.

\section{METHODS}

This prospective clinical study was conducted on patients receiving obstetrics care at Basaveshwara Medical College and Hospital from July 2016 to July 2018.

\section{Inclusion criteria}

- Pregnant women whose haemoglobin was less than $8 \mathrm{~g}$ were included in this study to determine the outcome of pregnancy in severe anaemia and determine the causes of anaemia.

\section{Exclusion criteria}

- Acute cases of obstetrical haemorrhages as in antepartum and postpartum haemorrhages,

- All medical and surgical high-risk factors except anaemia

- Those with history of preterm delivery.

The cases were included after counselling and obtaining a written informed consent. These patients were studied and evaluated in detailed with proper history taking, clinical examination and relevant investigations like complete blood count, peripheral smear, serum ferritin, serum iron, total iron binding capacity. Ethical clearance was obtained from the institutional ethics committee of Basaveshwara Medical College and Hospital for conducting the study. All the study group patients with $\mathrm{Hb}$ less than $8 \mathrm{~g}$ were admitted and background information, socio-demographic, anthropometry, obstetric profile and diet preference of the pregnant women were collected using questionnaire-cum-interview schedule. Blood pressure, maternal anthropometric measurements (height and weight) were taken using standardised techniques. Post-partum outcome of live birth, still birth, gestational age, congenital abnormality, type of delivery were collected. At delivery, neonatal anthropometry (weight, length, head circumference) were measured at birth using standardised techniques. Neonates with birth weight $<2.5 \mathrm{~kg}$ were defined as those with low birth weight $(1.50-2.49 \mathrm{~kg})$, further sub classifying the birth weight as very low birth weight $(1.00-1.49 \mathrm{~kg})$ and extremely low birth weight $(<1.00 \mathrm{~kg})$. Patients were appropriately treated with oral or parenteral haematinics or blood transfusion guided by their gestational age and haemoglobin level at presentation and by their tolerance to oral haematinics, after with advice on diet. After being adequately treated these patients were followed till their delivery and the outcome of pregnancy was noted wherever possible.

\section{Statistical analysis}

The data were analysed by using SPSS Statistics software Version 22.0. The quantitative measures are presented by mean and standard deviation and qualitative variables by proportions. Chi-square test, correlation coefficient, and logistic regression were used for testing significance. $\mathrm{P} \leq$ 0.05 was considered statistically significant.

\section{RESULTS}

A total of 200 pregnant anaemic patients with haemoglobin less than $8 \mathrm{gm} / \mathrm{dl}$ were included in the study. The patients were divided into two groups based on haemoglobin concentration at first presentation.

Patients with haemoglobin level less than $5 \mathrm{gm} / \mathrm{dl}$ were included in group $\mathrm{A}(\mathrm{N}=44,22 \%)$, and rest of the patients were included in group $\mathrm{B}(\mathrm{N}=156,78 \%)$. The findings of the two groups were then analysed and compared. Most of the women $(67 \%$ ) in group A with $\mathrm{Hb}$ (less than $5 \mathrm{~g}$ ) were unregistered, while $89 \%$ women were registered in group $\mathrm{B}$ with $\mathrm{Hb}$ (5.1-8g). Most of the women were young falling in the age group of 21-25 years with $40 \%$ in group A and $48 \%$ in group B.

Majority of the patients were from low socio-economic strata of society with $95.45 \%$ of patients with $\mathrm{Hb}$ less than $5 \mathrm{~g}$ and $93 \%$ of patients with $\mathrm{Hb}$ between $5.1-8 \mathrm{~g}$ belonging to class 4 and 5 of the modified B. G Prasad classification. In group A most of the patients were third gravidas $(45 \%)$. In group B most of the patients were either second gravidas $(41 \%)$ or primigravida $(26.28 \%)$.

In both groups' anaemia was diagnosed mostly at gestational age between 28 to 36 weeks. $65.9 \%$ in group $\mathrm{A}$ and $71.1 \%$ in group B belonged to gestational age between 28 to 36 weeks (Table 1). 
Table 1: Gestational age at detection of anaemia.

\begin{tabular}{|l|l|l|l|l|l|l|}
\hline $\begin{array}{l}\text { Gestational } \\
\text { age }\end{array}$ & \multicolumn{2}{c}{ Group A } & \multicolumn{2}{c|}{ Group B } & \multicolumn{2}{c|}{ Total } \\
\hline & $\mathbf{N}$ & $\mathbf{\%}$ & $\mathbf{N}$ & $\mathbf{\%}$ & $\mathbf{N}$ & $\mathbf{\%}$ \\
\hline$<12$ & 8 & 18.1 & 11 & 7.0 & 19 & 9.5 \\
\hline $12-27$ & 4 & 9.0 & 30 & 19.2 & 34 & 17 \\
\hline $28-36$ & 29 & 65.9 & 111 & 71.1 & 140 & 70 \\
\hline $37-40$ & 3 & 6.8 & 4 & 2.6 & 7 & 3.5 \\
\hline Total & 44 & 100 & 156 & 100 & 200 & 100 \\
\hline
\end{tabular}

In group A patients with $\mathrm{Hb}$ (less than $5 \mathrm{~g}$ ) $63.6 \%$ came first time in labour room. In group B, 64\% patients had less than four Ante Natal Care (ANC) visits.

Table 2: Distribution of patients according to causes of anaemia.

\begin{tabular}{|l|l|l|l|l|l|l|}
\hline Causes & \multicolumn{2}{l}{ Group A } & \multicolumn{2}{l|}{ Group B } & \multicolumn{2}{l|}{ Total } \\
\hline $\begin{array}{l}\text { Iron } \\
\text { deficiency }\end{array}$ & 34 & 77 & 120 & 76.9 & 154 & 77 \\
\hline $\begin{array}{l}\text { Vit B12 and } \\
\text { Folic acid } \\
\text { deficiency }\end{array}$ & 3 & 6.8 & 12 & 7.6 & 15 & 7.5 \\
\hline $\begin{array}{l}\text { Worm } \\
\text { infestation }\end{array}$ & 0 & 0 & 3 & 1.9 & 3 & 1.5 \\
\hline $\begin{array}{l}\text { Infection } \\
\text { Chronic } \\
\text { blood loss }\end{array}$ & 0 & 0 & 2 & 1.3 & 2 & 1 \\
\hline $\begin{array}{l}\text { Chronic } \\
\text { diseases }\end{array}$ & 4 & 9.0 & 9 & 5.7 & 13 & 6.5 \\
\hline $\begin{array}{l}\text { Sickle cell } \\
\text { anaemia }\end{array}$ & 0 & 0 & 2 & 1.2 & 2 & 1 \\
\hline Thalassemia & 0 & 0 & 2 & 1.2 & 2 & 1 \\
\hline $\begin{array}{l}\text { Bone marrow } \\
\text { depression }\end{array}$ & 1 & 2.2 & 0 & 0 & 1 & 0.5 \\
\hline Total & 44 & 100 & 156 & 100 & 200 & 100 \\
\hline
\end{tabular}

The common symptoms in group A were pedal edema and breathlessness on exertion, while common symptoms seen in group B were weakness, fatigue and pedal edema.75 patients in group B were asymptomatic at the time of diagnosis. 29 patients in group A and 112 patients in group B, had no any past-history.

There was a statistically significant difference in the packed cell volume, MCHC and $\mathrm{MCH}$ value in two groups. There was no statistically significant difference in MCV value. Microcytic hypochromic picture was commonly found in $61.36 \%$ of group A and $52.56 \%$ of group B patients.

In both group of patients, the commonest cause of anaemia in pregnancy was iron deficiency (Table 2). In group A, patients were mainly treated by blood transfusion, while in group B patients were treated mostly by combined treatment (blood transfusion and iron therapy).
The most commonly observed complications in the study were preeclampsia and eclampsia (46 cases), Preterm labour (46 cases) and IUGR (30 cases) (Table 3$)$.

Table 3: Distribution of patients according to maternal antepartum and intrapartum complications.

\begin{tabular}{|l|l|l|l|}
\hline Complications & Group A & Group B & Total \\
\hline Preeclampsia & 13 & 29 & 42 \\
\hline Eclampsia & 1 & 3 & 4 \\
\hline Antepartum haemorrhage & 0 & 2 & 2 \\
\hline IUGR & 7 & 23 & 30 \\
\hline Preterm labour & 12 & 34 & 46 \\
\hline PROM & 0 & 9 & 9 \\
\hline Oligohydromnios & 2 & 5 & 7 \\
\hline CCF & 6 & 1 & 7 \\
\hline Sickle cell crisis & 1 & 0 & 1 \\
\hline UTI & 2 & 3 & 5 \\
\hline Prolonged labour & 2 & 7 & 9 \\
\hline
\end{tabular}

In many cases there were combinations of complications like pre-eclampsia and IUGR and preterm labour and preeclampsia with IUGR. Postpartum haemorrhage, episiotomy wound infection and LSCS wound infection were the most commonly observed postpartum complications.

Table 4: Distribution of cases according to perinatal outcome.

\begin{tabular}{|l|l|l|l|}
\hline Outcome & Group A & Group B & Total \\
\hline Preterm deliveries & 18 & 41 & 59 \\
\hline LBW $(<1.5-2.5 \mathrm{~kg})$ & 21 & 59 & 80 \\
\hline VLBW $(<1.5 \mathrm{~kg})$ & 1 & 4 & 5 \\
\hline Intrauterine death & 1 & 1 & 2 \\
\hline Neonatal death & 2 & 4 & 6 \\
\hline Neonatal sepsis & 4 & 7 & 11 \\
\hline Pneumonia & 1 & 8 & 9 \\
\hline Jaundice & 1 & 6 & 7 \\
\hline Congenital anomalies & 0 & 0 & 0 \\
\hline NICU Admission & 7 & 22 & 29 \\
\hline ARDS & 1 & 3 & 4 \\
\hline
\end{tabular}

Most of the study cases delivered unassisted vaginally at term $36.36 \%$ in group A and 50.6\% in group B. While in full term vaginal delivery, episiotomy incision was taken in $13.6 \%$ of patients in group A and $15.36 \%$ of patients in group $\mathrm{B}$. The rate of full-term caesarean sections done was $9 \%$ in group A and $14.7 \%$ in group B. $4.54 \%$ in group A and $1.92 \%$ in group B had abortion. In group A there were 22 babies weighing less than 2500 grams which included 18 preterm babies and rest had intrauterine growth restriction. In group B there were 63 babies weighing less than 2500 grams which included 41 preterm babies and rest had intrauterine growth restriction. 2 (4.54\%) patients in group A with very severe anaemia had maternal death. There was statistically significant difference in mean birth weight in two groups of anaemic patients (Table 4). 


\section{DISCUSSION}

This Prospective clinical study was conducted to determine the outcome of pregnancy in patients with moderate to severe degree of anaemia with haemoglobin concentration $<8 \mathrm{gm} / \mathrm{dl}$, as the cut off limit for the study, because available data from India and elsewhere indicates that maternal morbidity and perinatal mortality rates are higher in women with $\mathrm{Hb}<8 \mathrm{~g} / \mathrm{dl}$.

$67 \%$ of patients in group A were not registered anywhere, they came first time in labour room. While $89 \%$ of patients in group B were registered and $11 \%$ were not registered. It means that many patients have not consulted to doctor and not taken treatment throughout their pregnancy, not even taken iron and folic acid tablets (IFA) during pregnancy. In the study of Couillet et al., found that $23 \%$ had not undertaken any ANC consultation during last pregnancy. ${ }^{5}$ As per IFA tablet supply and received, $75.7 \%$ had received IFA tablets. Shidhaye PR et al., found that $57.6 \%$ had received IFA tablets. ${ }^{6}$ In the study of Piyusha et al., only $71.7 \%$ had registered for antenatal care and $28.3 \%$ were not registered. ${ }^{7}$

Majority of patients in group A with ( $\mathrm{Hb}<=5 \mathrm{~g}$ ), 45.45\% are third gravidas, $18 \%$ are fourth gravid as while $20.45 \%$ are second gravidas. While in group B, $41 \%$ of patients were second gravidas, $23.71 \%$ were fourth gravidas and $26.3 \%$ were primigravida. In the study of Ahmad $\mathrm{N}$ et al., the severity of anaemia was more in those with parity of two or more. ${ }^{8}$ In the study of Usha singh et al., $55 \%$ multi gravid mothers showed anaemia in comparison with $45 \%$ primigravida who showed anaemia. ${ }^{9}$ In the study of R.G. Vivek et al., risk of developing anaemia in pregnant women with 3 to 5 pregnancies is increased when compared with those who had less than 3 pregnancies. 10 This could be due to the loss of iron and other nutrients during increased and repeated pregnancies and also the possibility of sharing of resources with the foetus. $55 \%$ multi-gravida mothers showed anaemia, in comparison with $45 \%$ primigravida who showed anaemia. In the study of Ivan E. A. et al., high percentage of anaemia was noted in those with multi-parity $(55 \%) .{ }^{11}$

Table 1 shows the duration of pregnancy at time of detection of anaemia. $65.9 \%$ of patients in group A, admitted in hospital between 28-36 weeks of gestation and $19.2 \%$ of patients in group A admitted between 1227 weeks of gestation. While in group B also majority of patients $71.2 \%$ were detected with anaemia between 28 36 weeks of gestation and $19.2 \%$ were detected with anaemia between 12-27weeks of gestation. Surveys done in different parts of India have revealed that $60-80 \%$ of women who belonged to low socio-economic status were anaemic in the last trimester of pregnancy. Study done by Balarajan U et al. and R.G Viveki et al. which also indicated that the prevalence of anaemia was higher in pregnant women in the third and second trimesters. ${ }^{10,12,13}$
$63.63 \%$ of patients in group A came in labour room first time, they had not registered anywhere before it, means they have not taken iron and folic acid tablets, throughout their pregnancy. While $29.5 \%$ of patients in group A has less than four antenatal check-ups. In group B, $64.1 \%$ of patients has less than four antenatal visits while only $23 \%$ of patients has more than 4 antenatal visits. In district level household survey done in 2006, most women in poorly performing states did not come for antenatal check-up. Many of those who came for antenatal checkup did not get IFA throughout pregnancy nor did they get 100 tablets. Majority of those who got the tablets did not consume all the tablets. ${ }^{14}$

There was statistically significant difference in $\mathrm{MCH}$ and $\mathrm{MCHC}$ value in both groups. But there was no statistically significant difference in MCV value in present study because dimorphic picture was present in more patients.

The commonest cause of anaemia in present study was iron deficiency anaemia as seen in table 2 and it is concluded from the peripheral blood smear picture and the red blood indices. $77.27 \%$ of patients in group A and $76.9 \%$ of patients in group B has iron deficiency anaemia. Macrocytic hypochromic picture suggestive of megaloblastic anaemia was seen in $6.8 \%$ of patients in group A and $7.6 \%$ of patients in group B. Apart from poor nutrition, infections too was cause of anaemia. $1.28 \%$ of patients in group B, had infection malaria, $1.92 \%$ of patients in group B had worm infestations which is quite common in India due to poor sanitary conditions, especially in low socio-economic group. 2 patients in group A and 4 patients in group B had chronic blood loss, in 6 patients 2 patients were suffered from bleeding piles while 4 had menorrhagia. 2 patients in group B, $1.28 \%$ of patients in group A had sickle cell anaemia. $1.28 \%$ of patients in group B had thalassemia. $2.27 \%$ of patients in group $\mathrm{A}$ had bone marrow depression. According to WHO iron deficiency anaemia is the cause of $75 \%$ of anaemic cases. ${ }^{15}$ In the study of Chowdhury S et al., the most common cause of anaemia in pregnancy was iron deficiency. ${ }^{16}$ It usually occurs due to low iron stores prior to pregnancy.

In the study conducted by Abdel aziem, et al., at a hospital in Kassala, women with severe anaemia had a 3.6 times higher risk of pre-eclampsia than women with no anaemia. ${ }^{17}$ It was recently observed that $17(17.7 \%)$ of 97 women with severe anaemia had gestational hypertension or preeclampsia and 2 (2.1\%) had eclampasia. 18 The greater the severity of the anaemia in pregnancy, the greater the risk of preeclampsia, preterm delivery, low birth weight and stillbirth. ${ }^{17}$ The susceptibility of women with severe anaemia to preeclampsia could be explained by a deficiency of micronutrients and antioxidants. Recent results indicate that reduction in serum levels of calcium, magnesium and zinc during pregnancy might be possible contributors to the development of preeclampsia. 
Table 4 shows the distribution of cases according to perinatal outcomes. Preterm deliveries were observed in $40.9 \%$ of patients in group A and $26.28 \%$ of patients in group B. Low birth weight was seen in $47.72 \%$ of patients in group A and $37.82 \%$ of patients in group B. $2.27 \%$ of patients in group A and $2.56 \%$ of patients in group B had very low birth weight. In the study of Kalaivani K.19 the risk of preterm delivery increased significantly with the severity of anaemia, with odds ratio of $1.4,1.4$ and 4.1 respectively for mild, moderate and severe anaemia. The corresponding risks for low birth weight and very low birth weight were 1.2 and $1.7,3.8$ and 1.5 , and 1.9 and 4.2 respectively.

A doubling of low birth weight rate and 2 to 3 fold increase in the perinatal mortality rates is seen when the $\mathrm{Hb}$ is $<8 \mathrm{gm} / \mathrm{dl} .{ }^{19}$ Lone et al., in a multivariate analysis of their study population showed that the risk of low birth weight babies in the anaemic population was 1.9 times higher (95\% $\mathrm{Cl}=1.0-3.4) .{ }^{20}$ Badshah et al., in their study found that there is highly significant difference $(\mathrm{P}<0.01)$ in the incidence of low birth weight babies among the anaemic mothers compared to non-anaemic mothers. ${ }^{21}$ Their study also showed that anaemic mothers are at increased risk of small for gestational age infants. $15.9 \%$ in group A and $14.1 \%$ in group B had NICU admission. NICU admission was mainly seen in neonates with low birth weight and those who were suffering from neonatal sepsis, pneumonia and jaundice. $9.09 \%$ in group A and $4.48 \%$ in group B had neonatal sepsis. $4.5 \%$ in group A and $2.56 \%$ in group B had neonatal deaths in present study. $2.27 \%$ in group A and $0.6 \%$ in group B had intrauterine death. While the neonatal deaths were predominantly a result of complications developing due to preterm deliveries and low birth weight. Intrauterine deaths were mainly observed in patients with severe preeclampsia or eclampsia due to abruption or severe fetoplacental insufficiency. According to Prema K, there is usually a 2 to 3 -fold increase in perinatal mortality when maternal haemoglobin levels fall below $8 \mathrm{gm} / \mathrm{dl}$ and 8 -10-fold increase when it falls below $5 \mathrm{gm} / \mathrm{dl}^{22}$

There were two maternal deaths (4.54\%) among 44 patients with very severe anaemia over the period of 2 years of the duration of the study. In India, anaemia is directly or indirectly responsible for 40 per cent of maternal deaths. There is 8 to 10 -fold increase in maternal mortality rate when the $\mathrm{Hb}$ falls below $5 \mathrm{gm} / \mathrm{dl} .{ }^{19}$ According to WHO in India about $4-16 \%$ of maternal death is due to anaemia, which is similar to present study. ${ }^{15}$ In Asia, anaemia (irrespective of severity) is the second leading cause of maternal death and account for $12.8 \%$ of maternal death independent of death due to postpartum haemorrhage.

There was statistically significant difference in mean birth weight in both groups indicating that the birth weight increased with increase in haemoglobin concentrations. Basically, a good haemoglobin concentration means a good nutritional status of the mother, resulting in a healthy baby from a healthy mother. Maternal anaemia is commonly considered a risk factor for low birth weight babies.

There were 6 neonatal deaths and 2 intrauterine deaths which were mainly as a result of complications of preterm births like neonatal sepsis, respiratory distress, pneumonia and jaundice.

\section{CONCLUSION}

This study reveals that severe anaemia which is commonly observed in the pregnancy in our country, gives rise to maternal and perinatal morbidities and mortalities. Therefore, anaemia in pregnancy is definitely a high risk needing aggressive antenatal treatment than the non-anaemic antenatal patients. Hence antenatal registration, early diagnosis and treatment of anaemia in pregnancy in our country, by various national and state level programs with improved outreach, can lead to a remarkable improvement in the pregnancy outcomes and will be foundation for further healthy population

\section{Funding: No funding sources}

Conflict of interest: None declared

Ethical approval: The study was approved by the Institutional Ethics Committee

\section{REFERENCES}

1. McLean E, Cogswell M, Egli I, Wojdyla D, Benoist de B. Worldwide prevalence of anaemia, WHO vitamin and mineral nutrition information system. Pub Health Nutri. 2009;12(4):444-54.

2. Sharma JB. Nutritional anaemia during pregnancy in non-industrialized countries: progress in obstetrics and gynaecology. 15th ed. Spain, Churchill Livingstone; 2003:103-11.

3. Centers for disease control, criteria for anaemia in children and childbearing aged women. MMWR 1998;38:400-404.

4. De Mayer EM, Tegman A. Prevalence of anaemia in the world. World Health Organization Qlty 1998; 38(3):302-16.

5. Couillet M, Serhier Z, Tachfouti N, Elrhazi K, Nejjari C, Perez F. The use of antenatal services in health centers of Fes, Morocco. J Obstet Gynaecol. 2007;27(7):688-94.

6. Shidhaye PR, Giri PA, Nagaonkar SN, Shidhaye RR. Prevalence of anaemia in postnatal women at a tertiary care teaching hospital in Mumbai. J Med Nutr Nutraceut. 2012;1(1):54-7.

7. Mahashabde P, Arora VK, Sharma S, Shahjada A, Dabhi HM. Prevalence of anaemia and its socio demographic determinants in pregnant women: A cross-sectional study in tertiary health care setup in central India. Natl J Community Med. 2014;5(1): 126-30.

8. Ahmad N, Kalakoti P, Bano R, Syed MMA. The prevalence of anaemia and associated factors in 
pregnant women in a rural Indian community. AMJ 2010;3(5):276-80.

9. Singh U, Singh SP, Niranjan A, Sharma S, Srivastava A, Singh HK. Prevalence of anaemia in pregnancy in rural western U.P: A prospective study. Indian J Pub Health Res Develop. 2011;2(2):60-3.

10. Viveki RG, Halappanavar AB, Viveki PR, Halki SB, Maled VS, Deshpande AI Ameen PS. Prevalence of anaemia and its epidemiological determinant in pregnant women. J Med Sci. 2012;5(3):216-23.

11. Ivan EA, Mangaiarkkarasi A. Evaluation of anaemia in booked antenatal mothers during the last trimester. J Clinic Diagnos Res. 2013;7(11):2487-490.

12. Park K, Park S. Textbook of Preventive and Social Medicine.23rd ed. 2000:325-451.

13. Balarajan U, Ramakrishnan E, Ozaltin A, Shankar H, Subramanian SV. Anaemia in low-income and middle-income countries. The Lancet. 2011; 378(9809):2123-135.

14. DLHS on RCH. Nutritional status of children and prevalence of anaemia among children, adolescent girls and pregnant women 2002-2004. Available at: http://www.rchindia.org/nr_india.htm 2006.

15. World Health Organization Prevention and Management of anaemia in pregnancy. WHO/FHE/MSM/93.5 Geneva; WHO,1993

16. Chowdhury S, Rahman M, Moniruddin ABM. Anaemia in pregnancy: Review article. Med Today 2014;26(1):49-52.

17. Ali AA, Rayis DA, Abdallah TM, Elbashir MI, AdamI. Severe anaemia is associated with a higher risk for pre eclampsia and poor perinatal outcomes in Kassala hospital, Eastern Sudan. BMC Res Notes 2011;4(1):311.

18. Rohilla, M, Raveendran A, Dhaliwal LK, Chopra S. Severe anaemia in pregnancy: a tertiary hospital experience from northern India. $\mathrm{J}$ Obstetrics Gynaecol. 2010;30(7):694-96

19. Kalaivani K. Prevalence and consequences of anaemia in pregnancy. Indian $\mathrm{J}$ Med Res. 2009;130:627-33.

20. Lone FW, Qureshi RN, Emanual F. Maternal anaemia and its impact on perinatal outcome in a tertiary care hospital in Pakistan. Trop Med Int Health2004;9(4):486-88.

21. Badshah S, Mason L, Mckelvie K, Payne R, Lisboa PJ. Risk factors for low birth weight in the public hospitals at peshawar, NWFP-Pakistan. BMC Public Health 2008;8(1):197-206.

22. Prema K, Kumari NS, Ramalakshmi BA. Anaemia and adverse obstetric outcome. Nutr Rep Int 1981;23:637-43.

Cite this article as: Lokeshwari $\mathrm{K}$, Arpana A, Mudigubba MM. A clinical study of impact of anaemia in pregnancy on maternal and neonatal outcome. Int J Reprod Contracept Obstet Gynecol 2019;8:273-8. 